\title{
A Multicenter Retrospective Study to Evaluate Safety and Efficacy of Tocopheryl Polyethylene Glycol Succinate Docetaxel in Various Cancers
}

\begin{abstract}
Introduction: In order to overcome the polysorbate induced hypersensitivity reactions with chemotherapy drugs, novel drug-delivery mechanisms have been developed in the last decade. D-alpha-tocopheryl polyethylene glycol succinate (TPGS) is formed by esterification of alpha-tocopheryl succinate and polyethylene glycol 1000. Materials and Methods: This was a real-world retrospective analysis designed to evaluate safety and efficacy of TPGS-docetaxel in various cancers. Patients hospitalized between June 2018 and May 2019 were included in the data set. While the efficacy was assessed by the Response Evaluation Criteria in Solid Tumors criteria, safety was assessed by the National Cancer Institute Common Terminology Criteria-adverse event (AE) criteria. Results: A total of 61 patients who received at least one dose of TPGS-docetaxel were incorporated into the analysis set. The dose of TPGS docetaxel ranged from $20 \mathrm{mg} / \mathrm{m}^{2}$ to $120 \mathrm{mg} / \mathrm{m}^{2}$, commonly prescribed dose being $75 \mathrm{mg} / \mathrm{m}^{2}$. While $25(40.98 \%)$ patients had a partial response, $17(27.86 \%)$ patients had stable disease. Five $(8.19 \%)$ patients progressed and $4(6.55 \%)$ patients died during the chemotherapy, which was adjudicated to be unrelated to the drug as opined by the treating clinician. AE were reported in 42 patients in the safety data set. There were no AEs pertaining to hypersensitivity reported during the study. One AE of Grade 3 hand foot syndrome was encountered. Conclusion: The preliminary evidence suggests that the novel TPGS-based docetaxel formulation is efficacious in various cancers, and importantly, it has an enhanced safety profile, as it is devoid of polysorbate 80 induced hypersensitivity reactions.
\end{abstract}

Keywords: Breast cancer, docetaxel, hypersensitivity reaction, non-small cell lung cancer, tocopheryl polyethylene glycol succinate

\section{Introduction}

Docetaxel is a second-generation taxane, derived from the inactive 10-deacetylbaccatin III, extracted from the European Yew tree (Taxus baccata). ${ }^{[1]}$ In the formulation of the innovator docetaxel, polysorbate 80 (Tween 80) is used as a solubilizer, stabilizer and as an emulsifier. The administration of docetaxel polysorbate 80 formulation is through intravenous route by further diluting it in ethanol/water. ${ }^{[2]}$

A meticulous review of literature suggests that polysorbate 80 is responsible for causing hypersensitivity reactions when used as a solubilizer, not only with docetaxel but also with other chemotherapy agents. ${ }^{[3,4]}$ Despite the premedications, $10 \%-20 \%$ of the taxane pretreated patients experience hypersensitivity reaction with docetaxel..$^{[5]}$ Based on the mortality data, the United States Food and Drug

\footnotetext{
This is an open access journal, and articles are distributed under the terms of the Creative Commons Attribution-NonCommercial-ShareAlike 4.0 License, which allows others to remix, tweak, and build upon the work non-commercially, as long as appropriate credit is given and the new creations are licensed under the identical terms.
}

For reprints contact: WKHLRPMedknow_reprints@wolterskluwer.com
Administration (US FDA) has issued a "black box" warning on the package insert. $^{[6]}$ In order to overcome these adverse reactions, D-alpha-tocopheryl polyethylene glycol succinate (TPGS), a novel drug-delivery mechanism, formed by esterification of alpha-tocopheryl succinate and polyethylene glycol (PEG) 1000, has been developed. ${ }^{[7]}$ TPGS is a US FDA approved pharmaceutical adjuvant, a derivative of Vitamin E, which is water soluble and chemically comprises of a hydrophilic head portion and lipophilic alkyl tail. ${ }^{[8,9]}$ TPGS acts as an absorption enhancer, emulsifier, solubilizer, permeation enhancer and a stabilizer. ${ }^{[7,9]}$ Importantly, when co-administered with a chemotherapy agent, TPGS has shown to enhance drug solubility and inhibit P-glycoprotein mediated multidrug resistance. ${ }^{[10]}$ In addition, properties of TPGS includes anti-cancer activity and anti-allergic actions mediated through

\footnotetext{
How to cite this article: Alurkar SS, Goswami C, Bokil K, Raut NV, Babu G. A multicenter retrospective study to evaluate safety and efficacy of tocopheryl polyethylene glycol succinate docetaxel in various cancers. Indian J Med Paediatr Oncol 2020;41:543-6.
}

\section{Shirish S Alurkar ${ }^{1}$, Chanchal \\ Goswami², Kamlesh Bokil ${ }^{3}$, Nirmal Vivek Raut ${ }^{4}$, Govind $\mathrm{Babu}^{5}$}

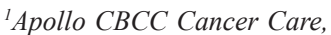
Gandhinagar, Gujarat, India, ${ }^{2}$ Medical Superspeciality Hospital, Kolkata, West Bengal, India, ${ }^{3}$ Dwidal Nursing Home, Pune, Maharashtra, India, ${ }^{4}$ Jupiter Hospital, Thane, Maharashtra, India, ${ }^{5} \mathrm{HCG}$ Bangalore Institute of Oncology, Bengaluru, Karnataka, India

Submitted: $21-O c t-2019$ Revised: 06-Apr-2020 Accepted: 01-Jun-2020 Published: 29-Aug-2020

Address for correspondence: Dr. Govind Babu, HCG Bangalore Institute of Oncology, \#8, P. Kalinga Rao Road, Sampangi Ram Nagar, Near Okalika Bhavan, Bengaluru - 560 027, Karnataka, India. E-mail: Govindbabu1138@ gmail.com

Access this article online Website: www.ijmpo.org

DOI: 10.4103/ijmpo.ijmpo_214_19 Quick Response Code:

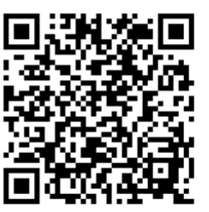


decreasing immunoglobulin $\mathrm{E}$ (IgE), leukotrienes and histamines. Hence, prudently, it has been formulated with chemotherapy agents such as paclitaxel, 5-fluro uracil, cisplatin and mitoxantrone. ${ }^{[7,11,12]}$ Figure 1 summarizes some properties of TPGS-docetaxel.

In the context of docetaxel, given that docetaxel by itself can cause hypersensitivity reactions, ${ }^{[13-15]}$ TGPS-based micelle drug delivery system may be advantageous, as it can encapsulate hydrophobic docetaxel and thereby prevent the exposure to nondesirable sites, leading to decreased hypersensitive reaction. Taking into account, first, that more drug is delivered at the site of action, ${ }^{[7]}$ and second, the anti-cancer and antidrug-resistant properties of TPGS, ${ }^{[10,16]}$ the new formulation may offer several advantages. Considering these factors and data from pharmacokinetic and pharmacodynamic study (unpublished data), the drug controller general of India has approved this formulation in 2013 without a Phase III study, as the active ingredient, docetaxel, was an established molecule with well-documented adverse events (AEs). However, in spite of this, it is important to know the efficacy and safety of the new formulation in real-world clinical settings and manage expectation postapproval. Therefore, we decided to observe the real-world usage, prescribing pattern and outcomes of docetaxel TPGS, a novel formulation without polysorbate 80 .

\section{Materials and Methods}

This was a real-world retrospective analysis designed to evaluate safety and efficacy of TPGS-docetaxel in various cancers. Patients hospitalized between June 2018 and May 2019 were included in the data set. Hospital medical records (electronic or physical), outpatient department registers and laboratory record values were used to extract the data. As this was a real-world experience study, we used broad inclusion criteria to get a precise clinical picture of the patients who were administered the novel TPGS-docetaxel preparation. Physicians had prescribed

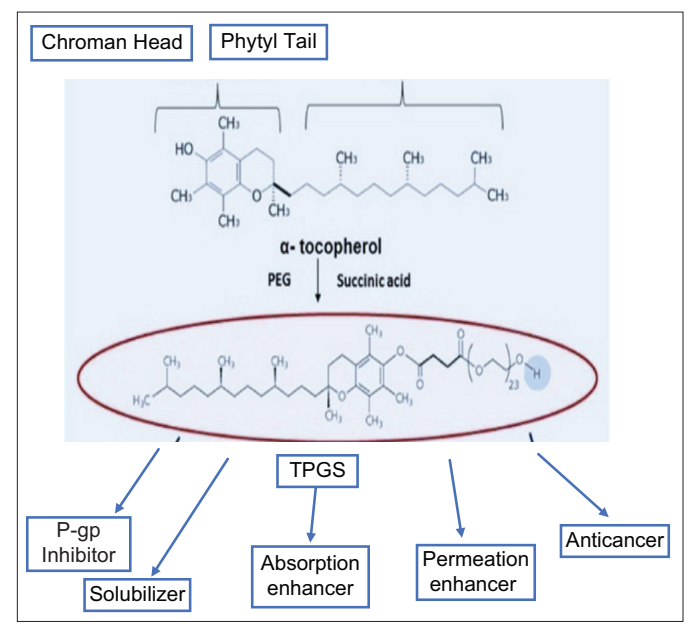

Figure 1: Properties of tocopheryl polyethylene glycol succinate-docetaxe ${ }^{[9]}$ the medication according to their preference based on clinical evidence and local hospital protocols. Patients of either sex, patients above 18 years of age, and all patients given TPGS-docetaxel for any of the following indications - (a) patients with locally advanced or metastatic breast cancer, (b) patients with hormone-refractory metastatic prostate cancer, (c) patients with locally advanced squamous cell carcinoma of the head and neck, (d) patients with advanced gastric adenocarcinoma, and (e) any other cancer which the investigator felt that TPGS docetaxel is useful, were included in the final analysis set.

Data were collected for knowing the patients baseline characteristics, comorbidities, dosage of docetaxel that was administered, efficacy and safety parameters. Further, to evaluate efficacy, the Response Evaluation Criteria in Solid Tumors 1.1 was used. ${ }^{[17]}$ The results were presented in terms of frequency percentage of patients for complete response, partial response, stable disease, and progressive disease categories. Severities of the AEs are graded from 1 to 5 according to the US National Cancer Institute Common Terminology Criteria-AE criteria version 3.0. ${ }^{[18]}$ The AEs were summarized as frequencies and percentages by type of reactions. Furthermore, in order to present the overall findings, descriptive statistics-percentages, frequency was used as appropriate.

\section{Results}

\section{Patient demographics}

A total of 61 patients who received at least one dose of TPGS-docetaxel were incorporated into the analysis set. Table 1 demonstrates the characteristics of the study population at baseline. The majority of the patients (43 [70.4\%]) were females and the average age of the patients was 48.8 years. In the analyzed cohort, 38 patients had a diagnosis of breast cancer $(62.29 \%)$ 10 patients had head and neck squamous cell carcinoma (6.1\%), 5 patients had gastric cancer (8.19\%),

\begin{tabular}{lc}
\hline \multicolumn{2}{c}{ Table 1: Patient demographics } \\
\hline \multicolumn{2}{c}{$\boldsymbol{n ( \% )}$} \\
\hline Sotal number of patients & 61 \\
Male & $18(29.5)$ \\
Females & $43(70.4)$ \\
Diagnosis & \\
Breast cancer & $38(62.29)$ \\
HNSCC & $10(6.1)$ \\
Gastric cancer & $5(8.9)$ \\
HRPC & $3(4.91)$ \\
Carcinoma esophagus & $1(1.63)$ \\
Carcinoma cervix & $1(1.63)$ \\
Leiomyosarcoma & $1(1.63)$ \\
Metastatic adenocarcinoma & $1(1.63)$ \\
Carcinoma gall bladder & $1(1.63)$ \\
\hline HNSCC-Head and neck squamous cell carcinoma; HRPC-Hormone \\
resistant prostate cancer
\end{tabular}


3 patients had hormone-resistant prostate cancer (4.91\%), and one patient each with carcinoma esophagus (1.63\%), carcinoma cervix (1.63\%), leiomyosarcoma (1.63\%), adenocarcinoma of unknown primary, and 1 (1.63\%) carcinoma gall bladder (1.63\%).

Tocopheryl polyethylene glycol succinate docetaxel prescription

The dose of TPGS docetaxel ranged from $20 \mathrm{mg} / \mathrm{m}^{2}$ to $120 \mathrm{mg} / \mathrm{m}^{2}$, with a most commonly prescribed dose of $75 \mathrm{mg} / \mathrm{m}^{2}$ for head and neck squamous cell carcinoma, hormone-resistant prostate cancer and gastric cancers. In breast cancer patients, in addition to the $75 \mathrm{mg} / \mathrm{m}^{2}$ dosage, the treating clinicians also employed a $60 \mathrm{mg} / \mathrm{m}^{2}$ dosage. Patients completed an average of 4.25 cycles of chemotherapy and each infusion with $100 \mathrm{ml}$ of normal saline took $30 \mathrm{~min}$.

\section{Efficacy results}

In the study, while $25(40.98 \%)$ patients had a partial response, $17(27.86 \%)$ patients had stable disease. Five (8.19\%) patients progressed and $4(6.55 \%)$ patients died during the chemotherapy [Table 2], which was adjudicated to be unrelated to the drug, as opined by the treating clinician.

\section{Safety evaluation}

AE were reported in 42 patients in the safety data set. All AEs are listed in Table 3. There were no AEs pertaining to hypersensitivity reported during the study. One AE of Grade 3 hand foot syndrome was encountered.

\section{Discussion}

Docetaxel is approved as the first-line treatment option for advanced or metastatic breast, head and neck squamous

Table 2: Efficacy of tocopheryl polyethylene glycol succinate - docetaxel in various cancers

\begin{tabular}{lc}
\hline & $\boldsymbol{n ( \% )}$ \\
\hline Partial response & $25(40.98)$ \\
Stable disease & $17(27.86)$ \\
Progressive disease & $5(8.19)$ \\
Death & $4(6.55)$ \\
Not evaluable & $2(3.27)$ \\
\hline
\end{tabular}

Table 3: Summary of adverse events $(n=42)$

\begin{tabular}{lcc}
\hline & $\begin{array}{c}\text { Total AE, } \boldsymbol{n} \\
\mathbf{( \% )}\end{array}$ & $\begin{array}{c}\text { AE of Grade 3 or } \\
\text { more, } \boldsymbol{n}(\mathbf{\%})\end{array}$ \\
\hline Fatigue & $20(47.6)$ & 0 \\
Neurosensory symptoms & $10(23.8)$ & 0 \\
Pedal edema & $5(11.9)$ & 0 \\
Neutropenia & $3(7.1)$ & 0 \\
Hand foot syndrome & $2(4.7)$ & 1 \\
Pleural effusion & $1(2.3)$ & 0 \\
Mucositis & $1(2.3)$ & 0 \\
Hypersensitivity/anaphylaxis & 0 & 0 \\
\hline
\end{tabular}

$\mathrm{AE}$ - Adverse event cell carcinoma and non-small cell lung cancer. Apart from the cancers mentioned above, docetaxel is also used in the treatment of numerous other malignancies. ${ }^{[6]}$ In general, patients in real-world settings tend to fare better than patients who are tested in controlled settings. ${ }^{[19]}$ Although in our study, we have not presented the bifurcated results based on cancer types, the overall results suggest that $42(77 \%)$ patients had a stable or partial response with TPGS-docetaxel. These results are agreeable with earlier studies, where patients on docetaxel had a response rate of $53 \%-82 \%{ }^{[20]}$ Expectedly, in the Phase III trial, when docetaxel was used as a single agent, the response rate was much lower between $30 \%$ and $42 \% .^{[20,21]}$

The most common AEs reported in our study was fatigue $(47.6 \%)$, followed by neurosensory symptoms $(23.8 \%)$, pedal edema $(23.8 \%)$, neutropenia (7.1\%), hand-and-foot syndrome (4.7\%), pleural effusion $(2.3 \%)$ and mucositis $(2.3 \%)$. It has to be emphasized that there were no hypersensitivity or anaphylactic reactions reported in this study. In terms of safety, the findings from a comprehensive drug review of docetaxel conducted by Figgitt and Wiseman ${ }^{[20]}$ reveals that hypersensitivity reactions were reported in $31.3 \%$ patients, which was nil in this study owing to the nonimmunogenic property of the novel formulation. Further, hematological toxicities were reported in $>90 \%$ patients receiving $100 \mathrm{mg} / \mathrm{m}^{2}$ dose. However, in this study, since most of the patients received a lower dose of $75 \mathrm{mg} / \mathrm{m}^{2}$, the incidence of hematological AEs was understandably lower at $7 \%$. Similarly, dermatological toxicities $(64.3 \%)$ fluid retention (46.7\%) and neurosensory AEs (47.9\%) were higher in the previous reports compared to our study.

Collectively, the efficacy of the novel TPGS docetaxel formulation is consistent with previous literature, implying a robust outcome benefit. Importantly, in line with our hypothesis, TPGS-docetaxel was associated with decreased rate of hypersensitivity reaction compared to polysorbate 80 containing formulation. The mechanism responsible for this reduced hypersensitivity can be attributed to (1) PEG component being less immunogenic, (2) distinct property of the tocopheryl (Vitamin E) component, which inhibits immune-mediators such as $\operatorname{IgE}$, leukotrienes and histamines. ${ }^{[22-24]}$

Although our study captured the clinical outcomes in terms of efficacy and safety, it was not without any limitation by virtue of its design. First, one could not capture progression-free or overall survival in these patients. Since, the data were retrieved from the medical records; the patient follow-up was limited till the subsequent visit to the hospital and not always till progression or death. Second, the overall data collection period was intended to capture the AEs and efficacy only on short-term basis. Third, by the very nature of the retrospective design, there is an inherent flaw of missing data for the analysis. Finally, there 
was no uniformity in dosing strength and frequency, and indications for prescribing, as every hospital followed their own protocol.

\section{Conclusion}

Although large data set of patients, who have been dosed uniformly with TPGS-docetaxel would be necessary to draw robust inference, preliminary evidence suggests that the novel TPGS-based docetaxel formulation is efficacious in various cancers, and importantly, it has an enhanced safety profile, as it is devoid of polysorbate 80 induced hypersensitivity reactions.

\section{Financial support and sponsorship}

Nil.

\section{Conflicts of interest}

There are no conflicts of interest.

\section{References}

1. Cortes JE, Pazdur R. Docetaxel. J Clin Oncol 1995;13:2643-55.

2. Engels FK, Mathot RA, Verweij J. Alternative drug formulations of docetaxel: A review. Anticancer Drugs 2007;18:95-103.

3. Picard M, Castells MC. Re-visiting hypersensitivity reactions to taxanes: A comprehensive review. Clin Rev Allergy Immunol 2015;49:177-91.

4. Schwartzberg LS, Navari RM. Safety of polysorbate 80 in the oncology setting. Adv Ther 2018;35:754-67.

5. Vasey PA, Atkinson R, Coleman R, Crqaford M, Cruikshank M, Eggleton P, et al. Docetaxel-carboplatin as first line chemotherapy for epithelial ovarian cancer. Br J Cancer 2001;84:170-8.

6. Docetaxel Prescribing Information. United States Food and Drug Administration; 2014. Available from: https://www.accessdata. fda.gov/drugsatfda_docs/label/2014/202356s0001bl.pdf. [Last accessed on 2020 Jan 16].

7. Neophytou CM, Constantinou AI. Drug delivery innovations for enhancing the anticancer potential of Vitamin $\mathrm{E}$ isoforms and their derivatives. Biomed Res Int 2015;2015:584862.

8. Zhang Z, Tan S, Feng SS. Vitamin E TPGS as a molecular biomaterial for drug delivery. Biomaterials 2012;33:4889-906.

9. Guo Y, Luo J, Tan S, Otieno BO, Zhang Z. The applications of Vitamin E TPGS in drug delivery. Eur J Pharm Sci 2013;49:175-86.

10. Dintaman JM, Silverman JA. Inhibition of P-glycoprotein by D-alpha-tocopheryl polyethylene glycol 1000 succinate (TPGS). Pharm Res 1999;16:1550-6.
11. Muthu MS, Kulkarni SA, Raju A, Feng SS. Theranostic liposomes of TPGS coating for targeted co-delivery of docetaxel and quantum dots. Biomaterials 2012;33:3494-501.

12. Zhu $\mathrm{H}$, Chen $\mathrm{H}$, Zeng $\mathrm{X}$, Wang $\mathrm{Z}$, Zhang $\mathrm{X}, \mathrm{Wu} \mathrm{Y}$, et al. Co-delivery of chemotherapeutic drugs with Vitamin E TPGS by porous PLGA nanoparticles for enhanced chemotherapy against multi-drug resistance. Biomaterials 2014;35:2391-400.

13. Mertens WC, Eisenhauer EA, Jolivet J, Ernst S, Moore M, Muldal A. Docetaxel in advanced renal carcinoma. A phase II trial of the National Cancer Institute of Canada Clinical Trials Group. Ann Oncol 1994;5:185-7.

14. Pazdur R, Lassere Y, Soh LT, Ajani JA, Bready B, Soo E, et al. Phase II trial of docetaxel (Taxotere) in metastatic colorectal carcinoma. Ann Oncol 1994;5:468-70.

15. Weiss RB, Donehower RC, Wiernik PH, Ohnuma T, Gralla RJ, Trump DL, et al. B. Hypersensitivity reactions from taxol. J Clin Oncol 1990;8:1263-8.

16. Youk HJ, Lee E, Choi MK, Lee YJ, Chung JH, Kim SH, et al. Enhanced anticancer efficacy of alpha-tocopheryl succinate by conjugation with polyethylene glycol. J Control Release 2005; 107:43-52.

17. Eisenhauer EA, Therasse P, Bogaerts J, Schwartz LH, Sargent D, Ford $\mathrm{R}$, et al. New response evaluation criteria in solid tumours: Revised RECIST Guideline (version 1.1). Eur J Cancer 2009;45:228-47.

18. Trotti A, Colevas AD, Setser A, Rusch V, Jaques D, Budach V, et al. CTCAE v3.0: Development of a comprehensive grading system for the adverse effects of cancer treatment. Semin Radiat Oncol 2003;13:176-81.

19. Suvarna VR. Real world evidence (RWE) - Are we (RWE) ready? Perspect Clin Res 2018;9:61-3.

20. Figgitt DP, Wiseman LR. Docetaxel: An update of its use in advanced breast cancer. Drugs 2000;59:621-51.

21. Sjöström J, Blomqvist C, Mouridsen H, Pluzanska A, Ottosson-Lönn S, Bengtsson NO, et al. Docetaxel compared with sequential methotrexate and 5-fluorouracil in patients with advanced breast cancer after anthracycline failure: A randomised phase III study with crossover on progression by the Scandinavian Breast Group. Eur J Cancer 1999;35:1194-201.

22. Schellekens H, Hennink WE, Brinks V. The immunogenicity of polyethylene glycol: Facts and fiction. Pharm Res 2013;30:1729-34.

23. Shahar E, Hassoun G, Pollack S. Effect of Vitamin E supplementation on the regular treatment of seasonal allergic rhinitis. Ann Allergy Asthma Immunol 2004;92:654-8.

24. Yamada K, Hung P, Yoshimura K, Taniguchi S, Lim BO, Sugano M. Effect of unsaturated fatty acids and antioxidants on immunoglobulin production by mesenteric lymph node lymphocytes of Sprague-Dawley rats. J Biochem Tokyo 1996;120:138-44. 